\title{
A Sociolinguistic Analysis of Gender Differences in (Snow in summer) story
} by Jane Yolen

\author{
إعداد إداد \\ المحاضر : سعاد علي ابراهيم الشهراني \\ محاضر في جامعه نجران لغويات تطبيقيه قسم اللغّه الانجليزيه \\ 1439 هـ
}

\begin{abstract}
This study attempts to highlight the impact of children's literature, as a socializing discourse, in constructing gender ideologies by using a critical discourse analysis approach to analyze a Snow in summer) story Jane Yolen's stories. The study has a number of objectives:
\end{abstract}


- To increase consciousness of the significance of language in the production, maintenance, and change of gender ideology and power relations;

- To raise an awareness of the workings of gender ideology in children's literature;

- To examine ways in which children's writers use language to inculcate a particular world view in the minds of their readers.

This study concluded that, Socialization is an important process of social conformity to integrate young members of a society into society itself. This is achieved by means of enforcing the norms and values legitimized by the sociopolitical system. Childhood is a crucial determining period in the life of a human being. It is not merely the time for basic education. Rather, it is, for and foremost, the time of learning about the nature of the world, how to live in it, how to relate to others, and how to think. Children's literature belongs, among a vast media, to the domain of cultural practices and ideologies with aim at socializing its readers. Hence, children's literature is regarded as a social discursive practice.

Key words: A Sociolinguistic - Gender Differences - Snow in summer - Jane Yolen

\section{Introduction}

Sociolinguistics offers a unique opportunity to bring together theory, description, and application in the study of language. Concerned about the social function of language, sociolinguistics builds on the notion that language use 
symbolically represents fundamental dimensions of social behavior and human interaction. The study of language in its social context, thus, tells about how social relationships within a particular community are organized. The development of sociolinguistics over the past several decades is characterized by the rise of particular specializations within the field that correspond to the emergence of more broadly-based social and political issues. Hence, the focus on themes such as language and gender corresponds with the rise of related issues in society at large and in feminist theory in particular.

\section{An Extensive overview about sociolinguistic and gender}

In the following the researcher presents an extensive overview about sociolinguistic and gender

\subsection{Sociolinguistics:}

Sociolinguistics is the subdiscipline of linguistics which deals with the relationship between language and society. Coined in 1950s, the term "sociolinguistics" attempts to bring together the perspectives of linguists and sociologists "to bear on issues concerning the place of language in society" and "to address, in particular, the social context of linguistic diversity" (Romaine, 2000, p. ix). For so long, modern linguists have treated grammars as increasingly divorced form the social lives of their speakers and have marginalized the social role of language. They have focused on the study of grammar and thus ruling out investigations of many interesting questions about how language functions in society; on the other hand, sociologists have treated society as if it could be constituted without language (Romaine, 2000, p. 19).

A. Hudson (1980) claims that the 'socio-' in 'sociolinguistics' is redundant, stating that "the study of language form an asocial point of view is scarcely worthwhile" (p. 19). Interestingly, Romaine (1994) clarifies that William Labov resists the term 'sociolinguistics' because it implies that there can be a successful 
linguistic theory that is asocial (p. 4013). On her part, Romaine names her book Language in Society rather than 'language and society' to emphasize the fact that "the study of society must accord a place to language within it at the same time as the study of language must take account of society" (Romaine, 2000, p. x).

It is worth highlighting here the distinction between sociolinguistics and the sociology of language. Although both study various aspects of language personal, stylistic, social, sociocultural, and sociological, the difference lies on the purpose of research. "The distinction is largely a matter of emphasis" Jack Chambers (1995, p.p. 10-11) points out. Sociolinguistics is concerned with the relationships between language and society with the aim of understanding the structure of language. On the other hand, the sociology of language refers to the study of the relationships between language and society with the goal of understanding the structure of society. Notably, there is a considerable area of overlap between both fields.

\subsubsection{Division of sociolinguistics:}

Different sociolinguists distinguish between theoretical and applied sociolinguistics. The first is concerned with formal methods for analysing the structure of speech communities and speech varieties, and providing a general account of communicative competence (Hudson, 1980, Trudgill, 1984, Romaine, 1994, 2000). On the other hand, applied sociolinguistics deals with "the social and political implications of fundamental inequalities in language use in various areas of public life" (Romaine, 2000, p. ix). A parallel division of the field is into macro- and micro-sociolinguistics (Hudson, 1980, Fasold 1984, 1990, Romaine, 1994, 2000). The macro level is also referred to as the sociology of language. Macro sociolinguistics takes society as its starting point. It deals with language as an essential element in the organization of communities and studies the way in which social groups organize their linguistic repertoires. Micro sociolinguistics 
begins with language and treats social forces as essential aspects influencing the structure of language. The current thesis locates its roots in the scope of the latter.

The approach of micro sociolinguistics operates quantitatively - linguistic variables are defined and realized in different forms and in different varieties then it operates correlatively - the different variants are correlated with sociological parameters. The most significant body of work that belongs to micro sociolinguistics is the research on urban social dialects as conducted by William Labov, Peter Trudgill, and Lesley Milory. Labov's book The Social Stratification of English in New York City (1966) is the first large scale sociolinguistic survey of an urban community. Labov introduces methods for investigating social dialects, viewing variations in the speech of and between individuals against the background of the community as a whole. The variations are conditioned by social factors such as social class, age, and sex.

There are several important findings of the quantitative research. One is "the intersection of social and stylistic continua" (Romaine, 1994, p. 4010). Style can range from formal to informal depending on social context, relationship of participants, social class, sex, age, physical environment, and topic. A further finding of quantitative sociolinguistics is that the use of variables is socially stratifying. For example, the social barrier between the middle class and the working class may be reflected in the usage of some linguistic features.

\subsection{Gender: A sociolinguistic variable:}

A major topic of sociolinguistics is the connection between "the structures, vocabularies, and the ways of using particular languages and the social roles of the men and women who speak these languages" (Wardhaugh, 1998, p. 309). Research on gender and sex in sociolinguistics and discourse analysis started in the early 1970s, when gender was established within sociolinguistic research as a social variable next to the already-existing variables of social class, age, nationality, 
ethnic affiliation, religion, and region. Two domains of language behavior in particular were examined: speech behavior of men and women on the phonological level, and interactions (conversational styles) between men and women in discourse (Wodak, 1997). While some of the research has described ways in which aspects of linguistic form vary depending on the sex of the speaker or addressee, other research has explained causes and effects of such variations and patterns of describing men and women as well (McCormick, 1994, p. 1353).

Sources of information about the relationship between language and its male and female users are diverse. First are texts written by people with a professional interest in language: lexicographers, grammarians, dialectologists, editors, writers of plays and novels (McCormick, 1994, p. 1353). Yet, other sources of information are found in a variety of texts produced by people whose main interest is not language, but rather, McCormick clarifies, includes: (a) differences in language use associated with the gender of the speaker/addressee; (b) differences in language use associated with the gender of the referent; and (c) efforts to change or reform language with regard to encoding gender.

There are two different views concerning the relationship between language and gender. Firstly, gender differences in language are a reflection of the way society works - such view has been extensively investigated by sociolinguistic research. The second view relies on language - a basic means of encoding ideas used to construct and maintain society. This latter view is held by some feminists who advocate language changes to eliminate social inequalities.

\subsubsection{Sex and Gender: the interplay of biology and sociology:}

It is important to distinguish here between sex and gender - a long investigated issue by feminists and gender researchers. 'Gender' is different from 'sex' in being about psychologically, socially and culturally expected characteristics rather than biology (Goddard \& Patterson, 2000, Livia, 2001). 
While the terms 'man' and 'woman' can refer to definitions based on biological differences, the terms 'masculine' and 'feminine' are always about expected gender characteristics - what men and women are supposed to be like. Notably, 'man' and 'woman' are nouns, suggesting 'people', while 'masculine' and 'feminine' are adjectives, suggesting qualities or attributes. Cameron (1997) notes that the starting debates on gender and sex was Simone de Beauvoir's observation in 1949, that one may be born female, but one becomes the kind of social being society defines as a woman (p. 22).

Thus, gender is a social construct. It exists not in persons but in transactions; it is a verb not a noun; i.e. it is something done - an action, not a statement. Such an idea of gender is referred to as the social constructionist view (Crawford, 1995, p. 12). As Livia (2001) puts it:

Gender is both a formal linguistic system involving nouns ... and a semantic system that refers to the cultural classification of human beings, their actions, and their attributes.... It is generally accepted by both literary critics and sociolinguists that gender is a cultural construct with different manifestations at different periods and in different contexts (p. 15).

Notably, there is a distinction between two types of gender systems: semantic and formal. Corbett (1991) explains that semantic gender reflects natural gender as an extralinguistic feature related to sex. On one the hand, semantic gender systems classify nouns referring to male humans and animals under the masculine gender, while those referring to female humans and animals under the feminine gender. As for the inanimate referents, they have metaphorical gender, and may be assigned to a neutral gender category. Livia (2001) adds that the term sexuisemblance (e.g. semantic gender) expresses the notion that nominal gender has semantic motivation (p. 17). On the other hand, formal gender systems do not depend on referential categories such as sex, but rather on the morphology or 
phonology of the noun itself. For instance, Latin nouns ending with -a (mensa, table; puella, girl) are typically feminine, while those ending with -us (populus, people; senatus, senate) are typically masculine independent of their meaning. English has only semantic gender.

\subsubsection{Sexism:}

The case about gender is that biology has been used to justify social judgments, to determine social roles and to give a way to discrimination within the social system at large - what is usually referred to as sexism. For example, the social role of mothering, Chambers (1995) explains, is traditionally assumed by women as a consequence of their biological ability of carrying and nursing, while men are traditionally charged of physical labor because they are bigger (p. 103). In the fight of sexual equality, any argument that women must do $\mathrm{X}$ and men do $\mathrm{Y}$ implies sexual bias, "as if biological imperatives were drawing the lines" (p.104). Biological differences seldom draw the lines between the social roles of men and women. Therefore, where gender largely bears on the distribution of roles and the credit or achievement of status, access to domains of social and economic activity is affected (McCormick, 1994, p. 1354).

With the term sexism, and with recognizing themselves as a social group and a suppressed minority, feminists seek to reveal the naturalized mechanisms of suppression and to offer means of fighting them. So, the feminist movement denies any injustice against women and so criticizes the assumed biological binary concept of sex - the presupposition that the differentiation between the two sexes is a natural fact represented in the body (McCracken,1997). To quote Wodak (1997):

On one hand, [feminists] dismantled myths of femininity, which, from an evolutionary point of view, were derived from traditional stereotypes such as the myth that all women are caring from birth in a biologically 
determined way. On the other hand, they criticized that ... the traditional division of labor between the sexes contributes towards the reinforcement and perpetuation of these myths about biologically conditioned gender traits. (Wodak, 1997, p. 2)

The naturalization of attributes connected to the sexes implies two issues: firstly, the binary of the sexes is an indisputable fact; secondly, the traits assigned to a sex are cultural constructs and therefore subject to change. The idea of 'change' is central - and will be further explored in a later section of this chapter (see sections $5,5.1)$.

\subsection{Socialization into gender identity}

Notably, one component of gender differences is cultural: one's gender role in the household, community or nation. McCracken (1997) maintains that role in itself is a cultural phenomenon since "One's role is one's social position with regard to other people [and] the result of legal or social traditions" (p.12).

McCormick (1994, p. 1358) demonstrates the achievement of late twentiethcentury development in psychoanalytic theory in France and its relation to socializing children into specific gender identity. A child acquires communicative competence as a boy or girl through several means. First is overt teaching or publication of normative codes. Second is modeling on adults' verbal behavior. Third is noting differences in adults' responses to the speech of boys and girls. Last is participating in peer subculture. Clearly, the role of language is undeniable. As an older generation transmits its culture to a younger one, a good deal of this culture is transmitted verbally. Speech becomes a vital instrument of socialization, Hudson (1980) clarifies:

Speech is an important factor in socialisation, not only through the information that it is used to impart, but also through the concepts which it requires the child to identify as meanings for the linguistic items he learns 
from other people's speech. In other words, the language which a child learns is closely related to the concepts he learns as part of his socialization. (p. 101)

Moreover, contemporary feminism has focused much attention on the issues of socialization into gender roles and of sexist discourse. Poynton (1989) clarifies that these issues are interrelated, "since everyday discourse with which children are surrounded from the day of their birth ... is a primary means by which socialization is affected" (p. 3).

\subsection{Language: A social phenomenon}

It is essential, therefore, to investigate language as a social phenomenon before discussing different manifestations of gender in language (Goddard \& Patterson, 2000, p. 67). It embodies cultural and social values. This means that when we speak we do not just say words, we speak our culture. By looking at the language used to describe something, we will gain an understanding of the way that thing is being conceptualized by that culture's members. Linguistic items, Hudson (1980) points out, are "one part of the culture as a whole" and as such are "likely to be associated with other aspects of the culture that are learned from the same people" (p. 96). It is important to realize that concepts are not real but are constructed using social experience. Such concepts produce consequences for users of the language. This view of language is a social constructionist one, i.e.,

...realities and subjectivities are constructed in and by language; ... subjects construct themselves and the worlds they inhabit in their everyday uses of language; ... power relations are constructed and deconstructed through these processes... (Threadgold, 2003)

\subsubsection{Linguistic determinism:}

For many centuries, the idea whether language is a reflection of the world or the world affects language has been an issue of debate. It will be useful to look briefly at the hypothesis of linguistic determinism - that the language one speaks 
determines one's perception of reality. The frequently discussed issue in this respect is Sapir-Whorf hypothesis. The linguist, Edward Sapir, and the psychologist, Benjamin Lee Whorf, in investigating different North American Indian cultures and the relation between language and thought, conclude that people are not simply passive recorders of what they find around them in language; rather, they impose their ideas on their environment as a result of the language they have. To put it simple, language is a determining thought and thus a perception of reality.

The Sapir-Whorf hypothesis suggests that when we acquire language, we acquire ways of thinking. "We dissect nature along lines laid down by our native languages... the world is presented in a kaleidoscopic flux of impressions which has to be organized by our minds - and this means largely by the linguistic system in our minds" (Goddard \& Patterson, 2000, p. 6). Therefore, linguistic structure is central to the formation of consciousness. Categories, such as gender, systematically elaborated in language, are not so much discovered in experience as imposed upon it because of, in Sapir's words, "the tyrannical hold of that linguistic form has upon out orientation in the world" (1929, quoted in Livia 2001, p. 11). This hypothesis allows for the influence of nonlinguistic factors, while attributing an important place to language and the categories it sets up. It follows, Livia (2001) explains, that "we cannot examine power relations, and the creation of individual, gendered subjects, without knowing what positions are constructed by a language and what other roles the same linguistic devices fill” (pp. 12-13).

Nevertheless, the Sapir - Whorf hypothesis has received many refutations, not to mention that both scholars changed their view radically from time to time. Among these refutations is the argument that the hypothesis cannot be true in any extreme way; otherwise language change would never be possible. Goddard and Patterson (2000) maintain that "New social practices and configurations ... cause 
new language to emerge" (p. 10). The need to name new experiences, thus, highlights the role of language to "validate and legitimise" a person's behavior and enhances the idea of 'change' (p. 10).

On the whole, the fact that a word lends a sense of reality to an idea proves how powerful language is in reading of the world. Language plays a crucial role in constructing shared view of reality held by speakers of a common language through: (a) naming aspects of the physical and social reality significant to the speakers through the process of categorization; and (b) ways of speaking that make possible enactment of social institutions and values (Poynton, 1989, p. 10). The question remains whether language can be said to influence the concepts or whether it simply reflects these concepts. The answer, Hudson (1980) argues, is "a bit of each" (p. 101).

\subsubsection{Categorization:}

Categorization refers to the process by which language organizes the cognitive system (the way the brain organizes thought and knowledge) to enable the location, retrieval, and use of the information it contains. Categories are the basis of the brain's cognitive system, and since they are labeled linguistically, this means that through the process of categorization, "language influences our thinking and reasoning" (Goddard \& Patterson, 2000, p. 50).

Therefore, one may argue that social categories and characterizations are human creations. The concepts associated with them are created, sustained and transformed by social processes that include labeling. Eckert and McConnell-Ginet (1995) claim that labeling is "only one part of a more complex sociolinguistic activity that contributes to constituting social categories and power relations among members of a community" (p.470).

Categories used in a society are a reflection of what the society believes to be important about people politically and socially - aspects of its ideology 
(Holmes, 1992, Goddard \& Patterson, 2000). On the one hand, a category can only exist in contrast with something else. For example, if there was only one sex then there would be no sex category. Equally, if race was not significant politically, then the use of the categories of "black" and "white" would not be used. On another hand, since categorization has a cultural basis, items which are characterized as similar in one culture may not be seen as such in another (Romaine, 2000). For example, gender as a category is shared by most cultures; but this does not mean that there are shared attitudes toward it. Thus, the cognitive model can vary between cultures. The idea that women are not suitable to do heavy work is relevant in cultures that see women as physically weak. In some cultures, Goddard and Patterson (2000) exemplify, women do heavy work, not because they are seen as equal to men but because they are seen as socially inferior. Therefore, the way we categorize and think is socially constructed, "based upon social experience and power relations rather than a literal representation of physical world and 'its natural order"' (Goddard \& Patterson, 2000, p. 54).

\subsubsection{Typicality: Stereotyping and Marking}

The categorization process is of importance because it clarifies the sociolinguistic aspect of gender. Related are two aspects of categorization involving the thinking and associated language features that are seen at work here: stereotyping and marking. Both notions are socially and culturally significant. Both employ language for their representations. And both share a common power which lies in the idea of implicitness. Implicit meanings are very powerful precisely because they are "unremarkable and therefore can become part of our automatic thinking" (Goddard \& Patterson, 2000, p. 28) and because "they remain unquestioned, and hence unproblematic" (Poynton, 1989, p. 3). Clearly, sociolinguistics profits from cognitive psychology and psycholinguistics. 


\subsubsection{Stereotyping}

Stereotyping is based on the theory of prototype. A prototype is the typical or central member of a category. According to this theory, a concept is not a set of necessary and sufficient features, but rather "a description of a typical instance of that particular concept" (Hudson, 1980, p. 78). In each category, some members (hyponyms) are more typical or central than other members. The central members are those which fit the cognitive model best. And these are the basis of the idea of the norm. For example, when the category 'bird' is mentioned, most people think of a 'sparrow' rather than a 'penguin' or 'ostrich', because sparrows fit the norm model of a bird more precisely, while penguins and ostriches are very atypical birds. However, it is worth noting that central status does not necessarily mean that items that are typical because they are common in one's experience. Rather, "they distill a number of qualities that we see as essential to the definition, and ... are at the basis of frequent cultural representations" (Goddard \& Patterson, 2000, p. 57).

\subsubsection{Marking}

The second concern to explore here connected to categorization and typicality is the language features involved in marking.

The gender category enforces a division of referents into masculine and feminine. Since the relationship between the two categories - male and female - is not an egalitarian but a hierarchical one, the category 'man' or 'male' is the norm and the category 'woman' or 'female' is the 'other', i.e. the marked version. Hence, the very existence of a linguistic gender system automatically contributes and perpetuates women as inferior to men or deviant at best. This assumption goes back to Sapir-Whorf hypothesis that the language one speaks affects one's perception of the world. McCormick (1994) maintains that marking is of interest to people concerned with the role of language in maintaining dominant societal perceptions because: 
... as long as words referring to women and not to men have to be marked for gender, the belief will persist that it is exceptional for women to be in these positions. As long as it is male terms, women's presence will tend to be obscured, as it is by the use of 'man' and 'he' as generics. (p. 1359-60)

Gender bias inherent in the use of 'he' as generic has been a central issue since the middle of the nineteenth century. Interest has increased with the rise of the feminist movement advocating women's liberation and equal rights (Livia, $1999,2001)$. The problem of the masculine generic is referred to as 'pronoun envy' by Anglophones and as 'phallogocentrism' in Francophones. The first, title of Livia's book, suggests that "the protester is misguided", while the second "recognizes both that gender is a central, indeed the central, component of language (as conceived by structuralist linguistics) and that it is organized around the mark for masculinity" (p. 5).

Moreover, there are forms of gender marking that are part of the morphological system of English and reflect a view of women as "deviant, abnormal or subordinate group" (Holmes, 1992, p. 337), although English is not a highly-gendered language if compared to French. One clear example is the suffixes 'ess' and 'ette' which are used for feminine occupational terms that are formally derived from the male version. In the following pairs of term (manager/manageress, usher/usherette, actor/actress, god/goddess, lad/ladette), the unmarked form is the male, and the marked form is the female. Goddard and Patterson (2000) and Romaine (2000) argue that not only does this suggest that the male figure is the 'norm' and the female one 'deviant', but the female form in the case of 'ette' implies diminution or imitation or lack of seriousness. This is similar with women's names diminutive of men's (e.g. Henrietta, Georgette, etc).

\subsubsection{Connotations: Linguistic production of gender}

Focusing on gender categorization, it is not difficult to prove that gender is something we do everyday and produce through language. One linguistic feature 
that exemplifies the importance of the linguistic production of gender is connotation (Goddard and Patterson, 2000, Romaine, 2000). Connotation is seen at work in adjectives and nouns; both can operate at different levels of description. Nouns, for examples, are seen as 'labeling' words, implying that things distinctively exist prior to their needing a name. By dividing the world into clearcut labels, nouns often mask a whole range of implicit descriptions which are very revealing of cultural values, i.e. 'connotation'.

Clearly, cultural stereotypes about old maids being losers in card games and in marriage market affect figurative uses for the term 'maiden'. The Oxford Advanced Learner's Dictionary's entry on figurative uses of the term 'maiden' defines them as sharing the meaning of 'being the first of its kind'. 'Maiden flight/ voyage/speech', all relate to the stereotype that "women should be virginal, inexperienced, intact, untried, and fresh in worldly as well as sexual matters" (Romaine, 2000, p. 107).

Moreover, connotations producing gendered view of the world are seen at work with the gendered pronoun reference marking the inanimate world. Dale Spender (1980) comments that cars and boats are seen as female because they are objects of status that have traditionally been under the control of men. Moreover, the physical attractiveness of these objects is described as in the case of describing women. On another level, the use of the pronoun "she" to refer to a country validates the idea of a matriarchal figure originating and sustaining its people (as in "mother country" and "mother tongue"). This idea is also encoded in "Mother Nature", a nurturing and protecting force (Goddard \& Patterson, 2000, p. 17). The question persists whether humans record objectively what they see, or they project onto the animal world aspects of human behavior, with all their attached ideas of relationships between male and female human beings. Clearly, Spender is talking 
about "a male perspective", a way of viewing the world that is encoded in the language people use as a "common resource" (Goddard \& Patterson, 2000, p. 16).

\subsubsection{Collocations}

More examples of gendered collocations are not hard to trace. Extending discussions on the connotations of 'spinster', Romaine (2000) studies the collocations of the term. She maintains that not only does the term itself have negative implications, but also the majority of words collocating with 'spinster' are negative as well. They include the following: "gossipy, nervy, over-made up, ineffective, jealous, eccentric, love-/sex-starved, frustrated, whey-faced, dried-up old, repressed, lonely, prim, cold-hearted, plain Jane, atrocious, and despised" (p. 109). Even with seemingly gender-neutral terms such as 'professional', connotations differ when collocating with men and women. Romaine (2000) explains that to call a man a professional would be a compliment, but to call a woman so is perhaps to refer to her a prostitute.

The current work is not a literary analysis of Yolen's works. Nor is this study a stylistic analysis of a contemporary storyteller's massive production. Rather, the literary data investigated in the research are used to validate the sociolinguistic hypothesis. The choice of contemporary children's literature is due to the importance of children's literature in socializing its readers into gender roles to meet a culture's expectations. Jane Yolen offers one possible worldview for boys and girls to grow in.

\section{Significance of the study}

The research contributes to the sociolinguistic research and to children's literature criticism. On one hand, it takes into account the most relevant textual, contextual, and intersexual factors (at micro level) which contribute to the production and interpretation of gender in a given text, and thus, the critique of social life at large (at macro socio-cultural practice level). The major success of the 
analysis is making visible the connections between properties of texts and social processes and relations (gender ideologies, power relations) which are generally not obvious to people.

\section{Objectives of the study:}

Objectives of the study may be summed up in the following:

- To increase consciousness of the significance of language in the production, maintenance, and change of gender ideology and power relations;

- To raise an awareness of the workings of gender ideology in children's literature;

- To examine ways in which children's writers use language to inculcate a particular world view in the minds of their readers; and

- To highlight the role of discursive practices in changing the socio-cultural sphere.

\section{5 - Study Questions}

To meet the above objectives, the thesis attempts to explore the following questions; answers are available in the analysis of each story:

- How are both genders represented in modern children's literature?

- How does language maintain gender ideology in Jane Yolen's Snow in summer) story?

- In what ways do revised tales produce alternative meanings and experiences for children?

- How is the shift in gender roles identified linguistically through the diverse representations of genders?

- How do female characters challenge hegemonic linguistic practices?

- In what ways does the linguistic behavior of female characters differ from/resemble that of male characters? 
- What ideologies might these differences/similarities imply? And what influence might they have on the children readers?

\section{Methodology}

This section presents the methodological procedures followed by the researcher to conduct the field study in terms of approach of the study, data of the Study and procedures of analysis as follows:

\subsection{Approach of the study}

The study starts from two sociolinguistic premises: (a) language is a social phenomenon in which the set of ideologies, values and beliefs of a certain society are embedded; (b) language is a powerful socializing agent for teaching the cultural novices (i.e. children) the community's social world, customs, institutions, and hierarchy. Among the dominant ideologies in a society is a social construct that plays a ruling role in people's life: gender. This study shares constructionist insight that gender identity emerges over time through discursive and other socializing practices. Giving the process of socialization such significance, the thesis attempts to highlight the impact of children's literature, as a socializing discourse, in constructing gender ideologies by using a critical discourse analysis approach to analyze a Snow in summer) story of Jane Yolen.

\subsection{Data of the Study}

I have chosen A famous writer for children of over two hundred books, Jane Yolen (1939 -) has been rewarded a considerable number of international awards and honors crowning her creativity. Her interest in fairytales and folktales has won her the titles of America's Hans Christian Andersen as well as a Twentieth-Century Aesop. With a belief in the power of fairy and folk stories to teach and mold, Yolen has contributed to the revision of the tradition and to the reclamation of the subverted heroes. She can be said to be a feminist children's writer who empowers both girls and boys by offering new way of seeing the 
familiar. Generally, Yolen's delineation of characters depends on overcoming stereotypical gender roles, and thus the language used for such portrayal is ideological.

The current work is not a literary analysis of Yolen's works. Nor is this study a stylistic analysis of a contemporary storyteller's massive production. Rather, the literary data investigated in the udy stare used to validate the sociolinguistic hypothesis. The choice of contemporary children's literature is due to the importance of children's literature in socializing its readers into gender roles to meet a culture's expectations. Jane Yolen offers one possible worldview for boys and girls to grow in.

"Snow in Summer" (2001). The story is concerned about the institution of the family when it becomes the source of discontent and pain to the heroine. Yolen reclaims her female hero her agency and stresses her inner, not outer, beauty. The hero transcends stereotypical gender roles, not by breaking them but by maintaining them and finding power in being a female. The story ends happilyever-after but with a different perspective of happiness.

\section{A Sociolinguistic Analysis of (Snow in summer)}

Snow in summer story begins with a little beautiful girl, Snow in summer, telling the account of her life after the death of her mother. The father, a traditional male figure, is in need of a wife; and so seeks to marry Rosemarie, "the queen of love and beauty" (p.18), apparently to look after his orphaned daughter, but also to compensate for the loss of his wife. However, summer's beauty sets the stepmother's jealousy on fire, and so she spares no effort to cause summer every pain. The daughter spends twelve years under the stepmother's "hard hands" (p.18); yet, she willingly takes care of cooking and cleaning, finding happiness in domesticity, in contrast with her stepmother who remains idle in terms of 
household chores. Summer finds compensation in the maternal comfort and kindness of her late mother's old friend, Miss Nancy.

The plot rises to a climax when, to the contentment of Summer, the father expresses his admiration of his daughter's beauty which resembles her "dear Mama" (p.19). The conversation takes place during a dinner that Summer herself prepares. But, the stepmother's jealousy is obvious and she decides and plans to get rid of her rival. Holding a radical and odd Christian orientation, the stepmother happens to go to Mt. Hosea Church, in which folks prove their faith by carrying poisonous snakes on their shoulders and letting their tongues down their cheeks. Thus, she decides to take Summer with her. Though the reason is not clearly stated, but predictably, she intends to get Summer poisoned or at least harmed by snakes. With Summer begging her father not to let her go, he agrees, not in fear of snakes, but of Mt. Hosea boys. This inspires the stepmother of another plan. She arranges for a date between Summer and a Mt. Hosea blonde fellow, convincing the father that Summer has grown into a beautiful lady and should meet men. So, against her will, Summer yieldingly goes to meet him in the woods, where he, enchanted by her beauty, grabs her hard and tries to kiss her. Yet, she hits him and manages to run deeper into the woods, escaping the societal subjugation, in search for identity.

Now starts another phase in Summer's life where she undergoes selfdiscovery of her own potential. She encounters seven small humpbacked miners. They receive her kindly and treat her like a royalty. So, she decides to stay with them like their little sister, happily taking responsibility of their cooking and cleaning and telling them the stories she has learned from Miss Nancy. They compensate her for Miss Nancy, and mostly become father surrogates. She stays with them seven years learning their profession of carving jewels, planting the garden and befriending animals. 
The story ends with punishment and reward. The denouement brings about a revolutionary resolution for the story. The stepmother appears, disguised like an ugly old women and knocks Summer's door. Yet, Summer recognizes her and so decides to put an end for her suffering. She offers the old woman an apple pie, while the latter bends to eat it, Summer gives her one single blow with the fry pan, upon which the woman falls dead. Surprisingly, Summer, with the help of one of the miners, buries her stepmother, and with her all the past agony and injustice. A state of equilibrium is attained with the father getting married to Miss Nancy and Snow in Summer choosing to stay in the house of the wood, serving and living with her seven fathers who need her keeping them alive and herself alive as well.

\section{Textual analysis:}

"Snow in Summer" presents an empowered young female who gains subjectivity, voice and agency through a number of linguistic features. The aim of this textual analysis is to examine these linguistic features and to trace how social practices are transformed into discourse about social practices.

\section{Textual subjectivity:}

The hero of the story, Snow in Summer, reaches a state of subjectivity and agency by (a) choosing a name for herself; and (b) seeing herself in the subject as well as the object positions. On the one hand, her name determines the relationship between herself and other characters. One the other hand, being the narrator of her own story, she is handed an authorial control of directing the text according to her own emotions, perceptions and ideology. The result is clauses representing processes that are mainly material and mental, modeling her physical experience and emotional and intellectual development.

\section{The name 'Snow in Summer':}

The concept subjectivity has to do with a variety of sociolinguistic forces that construct every individual. A subject is constructed by language and by the 
exterior forces that language asserts upon the individual. As illustrated in the previous chapter, three shades of female subjectivity are: birth images, naming and metaphor. These three elements have been combined in one name: 'Snow in Summer'. They stand for experiential, relational and expressive values.

On the experiential level, the name refers to "that white flower that covers the lawn like a poplin carpet" in summer (p. 17). It is a positive metaphor of whiteness, vastness, and beauty. In addition, it is expressive of this paradoxical sensation of warmth (summer) and cold (winter). Born in July "with a white caul" (p.17), the baby requires a name. So, her mother gives her the name of the flower, which is, expressively, "a warm, pretty name" (p.17), and to which the girl adheres. The relational value of the name is represented by its usage by different characters. Knowing that the mother wants her daughter to "answer to summer" (p.17) turns this syllable of the name (e.g. 'Summer') into her favorite and so becomes the unmarked form; any other form becomes deviant or marked and so affects and determines her relationship with other characters.

Firstly, the relationship between Snow in Summer and her stepmother is shaped in the stepmother's unfavorable use of the marked syllable 'Snow': ““'Snow!” It was a curse in her mouth. It was a cold unfeeling thing." (p.17). The natural phenomenon of snow, as associated with coldness, numbness and lifelessness, results in the girl's losing face and accordingly her inability to love her stepmother, even though she tries for the sake of her father. It is not difficult to prove that the stepmother deliberately chooses this syllable of the name to cause Summer embarrassment. For example, when the stepmother introduces her to the men of Mt. Hosea church, she does not tell them her "true name", and so the blonde fellow asks for "Snow" (p. 20). It is interesting to note that associating the full name 'Snow in Summer' or its unmarked version 'Summer' with "truth" 
validates the assumptions that (a) the stepmother attempts to subvert Summer's identity; and (b) naming is a matter of subjectivity.

On the other hand, the normative syllable of the name, 'Summer', used by people who care for and love the heroine, preserves her face and brings them all together in terms of relations. Firstly, Miss Nancy, her mother's closest friend and her future stepmother at the end, calls her "Summer dear" (p. 22). It is no surprise that the two female characters are so close and intimate that Summer always speaks of her and her stories during her stay with the miners, cherishes her memories and follows her advice. Miss Nancy, thus, becomes a mother surrogate. Secondly, the early acquaintance between Summer and the seven miners is initiated by confirming her subjectivity. She introduces herself as "Snow in Summer. Like the flower." (p. 21). As they call her "Summer", with "softness and a dark grace" (p.21), she no longer sees them as ugly even though they are in fact ugly. This very single choice of her favorite name shortens the distance between them and foretells of future intimacy.

Lastly, choosing a name for one's self is a strong proof of retaining subjectivity and enacting power. The heroine chooses her favored syllable "Summer" when her stepmother comes in disguise to the little house in the wood. On one level, she recognizes her stepmother and so determines to annoy her because this is the syllable that the stepmother avoids to use. On another level, the heroine, by this part in the story, has gained a great deal of self-assertion and positive self-image after seven years of independence and self-discovery; choosing "Summer" is an expression of such accomplishment. However, as she still reads "Snow" on the old woman's lips, her feelings of hatred and despise for her stepmother are maintained. The woman has not changed; so Summer decides to get rid of her before the women carries out her murderous unspoken-of plan.

Narrator's agency: 
One definition of "narrative agency" is the speaker or voice of the narrative discourse. He or she is the agent who manages the exposition, who decides what is to be told, how it is to be told (especially, from what point of view, and in what sequence), and what is to be left out. Jahn (2002) explains that one function of narrative discourse is an "emotive" or "expressive" function (expressing subjectivity and voice of the narrator; the psychological, sociological and ideological ramifications of the narrator's attitudes, which may range from neutral to highly charged). "Snow in Summer" is narrated from a first person point of view (Summer's). The main female character, thus, becomes the focalizer, i.e. the agent whose point of view orients the narrative text. The text is anchored on the focalizer's point of view as it presents (and does not transcend) her thoughts, reflections and knowledge, her actual and imaginary perceptions, as well as her cultural and ideological orientation. In turn, focalized narration tends "to draw the reader into subject positions identical to those of the narrator" since the reader is shown the world through the character's eyes (Talbot, 1995, p.30). Clearly, attaining this authority is one source of confirming Summer's subjectivity and agency.

Snow in Summer narrates the account of her life. The text is declarative with Summer becoming the dominant Theme. The voice is active all through and agency is clear. The experiential function of clauses, where pronoun "I" is in the Subject position, represents patterns of experience that stand mainly for material and mental processes - these two process types predominate in the story. Firstly, in material-process clauses the heroine plays the participant role of the Actor. She is physically active throughout the story. In the beginning, she is responsible for the household chores, as in (bold highlights Subject and Process):

- “...with the chicken I had cooked” (p.18)

- “...with the taters I had boiled" (p.18) 
- "So I did [i.e. clear the dishes]" (p.19)

Then, when she is attacked by the blonde man in the woods, she is again active and even violent as the situation requires of a girl in danger. She rescues herself without any external help:

- "I kicked him in the place Miss Nancy told me about" (p.20)

- 'I ran away ... But I kept running ... I ran and ran even deeper into the woods" (p.20)

Summer's stay with the miners is a period of hyper activity and continuous giving. She is the lady of the house, putting things into order. Her activity extends outside home as she grows a whole garden. Clearly, she has developed a self-image of responsibility. Hence, the experiential value of the clauses reflects such an accomplishment in terms of material processes:

- "So I followed them home." (p.21)

- "I cooked for them and cleaned for them...." (p.21)

- "I tidied and swept and made-up the dinner." (p.22)

- “Then I'd go outside to play." (p.22)

- “...there I grew everything” (p.22)

Now that she has developed physical maturity, Summer is capable of putting an end to her past pains and of retaining what she has lost. The murder she commits, which is represented experientially by material-process clauses, marks the peak of empowerment and activity. She actualizes the self-made happiness that Miss Nancy has always advised her:

- "I fed her a deep-dish apple pie..." (p.22)

- "I felled her with a single blow of the fry pan." (p.22)

- “And so I did. [i.e. make her own happiness]" (p.22) 
The ending of the story witnesses Summer in her typical material activity. Mostly, she continues on the road she has chosen and returns back to the miners, this time willingly and without obligations:

- "I went to the wedding" (p.22)

- "I went back home alone" (p.22)

Moreover, Summer models her experience with the world around her in terms of mental processes, where she plays the role of Senser. Her mental abilities are apparent in her comments on the events around her throughout the narration of her story. Firstly, her hatred to her Stepmother is clear in negated Affection processes, such as:

- "I didn't love her" (p.17)

- “I couldn't love her" (p.17)

Her Affection for other characters and for Lord is also expressed:

- 'I loved sitting next to Miss Nancy"(p.17)

- "I love the Lord mightily" (p.17)

- “Oh, I missed my Papa now and then” (p.21)

Summer's thinking never stops; she is conscious of the different Phenomena around her and is capable of determining her feelings and thoughts. Her perception, affection and cognition are alert. She reaches an advanced stage of sensing and judging. This is what enables her to take the decision of leaving home and, by the end, killing the stepmother. Examples of mental processes are:

- 'I didn't think much of it at the time [i.e. her Stepmother's jealousy]" (p.18)

- "I do not think she liked what she saw [i.e. Summer's beauty]" (p.18)

- "None in fact that I could remember [i.e. her father's praise in the past]" (p.19)

- 'I wasn't to know it that night [i.e. her Stepmother's plot]" (p.19) 
- “I am feared of snakes"...(p.19)

- "...though I did not really want to go [i.e. with the blonde man]" (p.20)

- " 'I did not mourn what I did not have." (p.22)

- " "I knew her at once." (p.22)

- "I saw "Snow" on her lips." (p.22)

Not only does Summer recognize her own feelings towards others, but also, others' feelings and manners towards herself. As she develops, she acquires an ability to judge others' actions and identify their realities, as revealed in the expressive value of words highlighted in bold:

- " "[Stepmother] did not say it nicely" (p.17)

- "It was a curse in her mouth. It was a cold unfeeling thing." (p.17)

- "it killed [Miss Nancy], too, when Mama was took by death." (p.17)

- "Papa besot with my Stepmama. He thought she couldn't do wrong." (p.17-8)

- “Papa said, as if surprised by it" (p.18)

- "It was not a compliment in her mouth" (p.20)

- “And it was not the truth" (p.20)

- "It was my stepmama in disguise" (p.22)

It is interesting also to examine how Summer is objectified in the story. After all she is the narrator; thus, seeing herself in the Object position (a third person) highlights the concept of subjectivity. Interestingly, referring to herself, Summer does not recognize her supremacy even though she is at the prime of her beauty. Identifying herself with a child refers to her innocence and her concern for inner feelings:

- "If I thought of myself at all those days, it was a lanky gawky, coltish child" (p.18) 
Moreover, there are a number of forces acting physically and mentally upon the heroine and she recognizes them. So, Summer is put as Object (highlighted in bold). The first force is her stepmother.:

- "But my Stepmama, who took me in hand just six month after Mama passed away, only spoke the single syllable of my name" (p.17)

- “... for the first time my Stepmama looked - really looked - at me" (p.18)

- "She sent me out to walk with him" (p.20)

- My Stepmama wanted me to be with him. And that plum frightened me" (p.20)

The second is the blonde man:

- "He asked for me" (p.20)

- "he pulled me to him and tried to kiss me with an open mouth" (p.20)

Yet, by contrast there are a number of forces acting for her, caring and loving. This is best represented in the miners; clauses where they are Subject and she is Object stand for material, behavioral, mental, and relational processes. They help her develop in these directions; therefore, Summer realizes that the miners are her source of power and life:

- "They were as good to me and as kind as if I were their own little sister" (p.21)

- "They taught me how to carve out jewels" (p.21)

- "They showed me the secret paths around the mountain" (p.21)

- “They warned me about strangers" (p.21)

- "one of the miners would always comfort me and sing for me" (p.21)

- "My little man helped me bury her out back" (p.21)

- “To keep me alive, too" (p.22) 
It is worth highlighting that the relationship between Summer and the miners is reciprocal. For all they give her, she returns. Her awareness of their major influence on her independence and self-image directs her to choose staying with them for good. The last lines in the story represent their need for one another in the repetition of the mental process "need" and the material process "keep":

- My seven little fathers needed keeping. They needed my good stout meals. And they needed my stories of magic and mystery. To keep them alive. To keep me alive too.” (p.22)

Finally, it is worth noting that Summer, as a narrator, commits a number of errors lexically and grammatically. Firstly, on the lexical level, she either invents some vocabulary such as: "rattlers" to mean "folks of Mt. Hosea who use rattlesnake to prove their faith', and "copperheads" to mean 'a type of poisonous snake'. She also misspells other vocabulary: such as using "pizzen" instead of 'poison', "checks" instead of "cheeks", and "opined" instead of 'gave an opinion'. On the grammatical level, she commits a number of errors: "was took", "was besot with", and "they was hitched". Lastly, frequently, the tense of narration switches from past to present. Apparently, the story is narrated when the heroine already takes her decision to stay with the miners. At this stage, she is twenty one years old. But, there is no definite indication of the true time of narration, for probably she relates her story in a later stage. Moving from past to present tenses may be justified that she is still affected by her previous experience. Mostly, such an authorial control to breach lexical or grammatical roles is one way to assert her subjectivity.

\section{Classification schemes:}

The famous antonyms 'beauty' and 'ugliness' and their collocations with 'love' and 'hatred' are constructed ideologically in the story in favor of highlighting the supremacy of inner beauty and the empowerment of the female 
hero. Since what is under study now are two abstract concepts related to personal evaluation, 'beauty' and 'ugliness' carry more expressive than experiential values - although sense relations of synonymy and antonymy fall within the experiential value of words. The antonymy is validated in the following equation schemes:

1. outer beauty $=$ inner ugliness

2. outer ugliness $=$ inner ugliness

3. outer beauty = inner beauty

4. outer ugliness $=$ inner beauty

Fig 1 : Beauty vs. ugliness collocation schemes in "Snow in Summer"

Scheme 1 applies to the stepmother and is validated by scheme 2. To illustrate, the stepmother is a beautiful woman as attested by everyone: "She was a beautiful woman, everyone said" (p.17). Being the "queen of love and beauty" (p.18) wins her the father's heart. The collocation of "love" with "beauty" exhibits a two-direction relation: the first is a result of and a proof for the second. The husband loves Rosemarie because she is beautiful; because he loves her, he has to prove it by praising her beauty all the time. The other part of the equation has to do with the woman's tyranny with her stepdaughter and is best represented by Miss Nancy's comment: "Looks ain't nothing without a good heart." (p.17) - a notion that is further developed by Summer as she refers to her Stepmothers' physical qualities as "soft nothings" (p.18). Clearly, referring to "looks" as "nothing" serves the purpose of undermining outer beauty. Finally, the first scheme is validated by the second when the stepmother disguises like an old ugly woman ("with crosseyes and a mouth full of black teeth" (p.22)). It is this collocation of inner and outer ugliness that dooms her to death.

"Good heart" is, therefore, a basic ingredient in the beauty equation. This is validated by schemes 3 and 4 . Scheme 3 represents Snow in Summer: she is physically beautiful, although there is no description of this beauty except twice in 
the story. Firstly, her father is surprised that she is turning into a beautiful "child" (p.18); secondly, her stepmother cunningly justifies her relationship with the rattlers to find a groom for Summer who is now "A beautiful woman" (p.21) even though Summer at that time is only thirteen. There is an indication here that Summer's beauty, if it does not surpass, competes with the Stepmother's. At any rate, the stress is, thus, on Summer's outer qualifications at household: cooking, cleaning, etc. and on her inner qualities: as care, responsibility, compassion, endurance, etc. Her inner and outer beauty gains her the love of everyone and, paradoxically, the hatred of her stepmother. As for scheme 4, it stands for the case of the miners. They are "ugly as an unspoken sin" (p.21) but they win the love of Summer and the reader by their care and devotion to Summer. Clearly, the story, building on the ideological representation of two aspects of reality: beauty and ugliness, recommends classification schemes 3 and 4.

\section{Situational context}

The situational context of the story is best understood by exploring how men and women are portrayed within the social space. The society in the story is a patriarchal one holding the stereotypical view of women as beautiful domestic creatures. Male members of this society are depicted negatively, chasing seductive females, starting from Summer's father and ending with the Mt. Hosea rattlers. The first is blinded by his wife's glamorous physical appearance and does not feel the suffering of his only daughter. The others are creepy ill-mannered fellows. Interestingly, there is no clue about the father's or the rattlers' occupation. Their social role is delineated in relation to women. Interestingly, all male characters are not named, while female characters are: Rosemarie, Nancy, and Snow in Summer. Yet, the positive male social actors are the miners. They are productive and humane. They are named in terms of their social role and profession. Any way they do not belong to the same patriarchal society. Clearly, in a society where male 
figures do not offer physical and emotional protection, Summer has to find a substitute - i.e., the miners.

As for female characters, they are portrayed as more active and powerful than the male ones. The stepmother, though fails to play her social role as a mother surrogate for Summer, is active in terms of cruelty and evil. She enacts her power on the stepdaughter and prolongs the distance between them through long years of oppression. She also fails in her social role as a wife:

"She would have rather heard those soft nothings said about her than to talk of any of the things a husband needs to tell his wife: like when is dinner going to be ready or what bills are still to be paid." (p.18)

It is worth noting that Summer seems to accuse her father mainly, not the stepmother, for the latter's failure to play her role: "Papa besot with my Stepmama". He has based his marriage on physical infatuation not on familial interest. Clearly, in such patriarchal society, a wife's domesticity is commonsensical; maintaining the social order within the family necessitates a hardworking caretaker female. Ironically, the daughter maintains this order and succeeds to do so. In contrast to the Stepmother, Miss Nancy is resourceful and powerful in terms of wisdom. The fact that she is not physically described highlights the supremacy of intellect over beauty; her triumph (i.e. winning marital happiness) at the end emphasizes this notion.

\section{Intersexual Context:}

Studying the intertextual context of the story puts "Snow in Summer" as a direct revision of early image of passive femininity in fairytales and children's literature as represented in the famous story of "Snow White". The text contradicts the traditional tale through a considerable number of issues; all these differences serve the focusing of events on the main character, pave the way for her selfdevelopment, and justify her murder: 
1. Snow in Summer does not belong to a rich or a royal family, as in original tales; and there is no clue about the financial status of her family.

2. The mirror is eliminated completely from the story; and there are no magical tricks the stepmother resorts to. This would emphasize the fact that the stepmother is motivated by her own inner ugliness to get rid of Summer and not by external forces - which highlights the conflict in the story.

3. Magic is replaced by an odd Christian creed; this adds further ugliness on the stepmother who takes religion as a mask for her wicked intentions.

4. Summer is able to recognize her stepmother coming in disguise. She is the one to offer her food (apple pie). She decides to get rid of her source of misery before the woman even starts to carry out her plan.

5. The huntsman in the old version sent by the stepmother to kill the girl is replaced by a suitor who takes advantage of the girl's irresistible beauty.

6. There is no knight or prince to save the heroine for she has played the role herself.

7. Miss Nancy is a new character that serves a mother surrogate and the First Teacher. It is her advice that Summer follows and so she deserves a reward by the end.

8. The question of marriage disappears as Snow in Summer does not seek marriage even though her problems are over; she dances with many handsome men but marries none. Marriage is replaced with Summer's choice of comradeship with the miners. Thus, the ending of the story is freedom not marriage.

Mostly, there are two important elements of the intertextual context of Yolen's revision that need further scrutiny. Firstly, the new Snow White, represented in Snow in Summer, celebrates her stereotypical feminine features: compassion, consideration, domesticity, etc., gaining power from these. Yet, this 
same image shocks the reader because Summer's means of transcending traditional stereotyped role is a cold-blooded unregrettable murder, which is not only an antifeminine act, but an anti-human one. Killing is after all a crime, regardless of the gender of the murderer. Leaving her unpunished or unregretful may serve Yolen's ideological stand of empowering females. But this would negatively affect the young readers in terms of justifying the means as long as the end is satisfactory.

Secondly, the intensions of the stepmother are not spoken of. Readers do not know why she wants to get rid of Snow in Summer, why she wants to take her to Mt. Hosea Church, why she arranges for a date with the blonde fellow, or why she seeks her rival even though the latter has been far away for seven years. These intentions are all present in the traditional tale. Yolen's text, thus, presupposes that reader know the historical grounding of the original. Otherwise, Summer's crime is not well-justified.

\section{Conclusion}

Socialization is an important process of social conformity to integrate young members of a society into society itself. This is achieved by means of enforcing the norms and values legitimized by the sociopolitical system. Childhood is a crucial determining period in the life of a human being. It is not merely the time for basic education. Rather, it is, for and foremost, the time of learning about the nature of the world, how to live in it, how to relate to others, and how to think. Children's literature belongs, among a vast media, to the domain of cultural practices and ideologies with aim at socializing its readers. Hence, children's literature is regarded as a social discursive practice.

Gender is not only inherited in the individual but it is constructed in a culture where a collection of symbols and stereotypes start to define what it is to be male and female. Since gender is a social construction and reading is a social practice, therefore gender issues are unavoidably present in reading. Gender plays 
a major role in the children's literacy. When we expose children to stories that portray males and females in specified gender roles, we are encouraging them to limit their behavior and goals to those stereotypes. The characters found in children's literature are portrayed in such a way that they are able to influence a child's mind about gender issues. Children need to develop skills that enable them to become critical thinkers, as they will continually be confronted with gender distorted, stereotypical literature.

The principal code of socialization is language. Language is the most common form of social communication. It is through language that the subject and the world are represented in literature. It is through language that literature defines the relationship between child and culture. The notion of a narrative without ideology is unthinkable. Meaning is not the product of a self-contained linguistic system, but rather a part of a complex interconnection of language and society. There is a need for a critical methodology able to examine the interrelated issues of ideology and texts, in order to disclose the processes and effects of representations and definitions. One means is to incorporate a critical linguistic approach. 


\section{References}

\section{Primary Resources:}

Yolen, J. (2001). Snow in summer. In Sister Emily's lightship and other stories (pp. 17-22). New York: Tor Books.

\section{Secondary Resources:}

Cameron, D. (1997). Theoretical debates in feminist Linguistics: Questions of sex and gender. In R. Wodak, (Ed.), Gender and discourse (pp. 21-36). London: SAGE.

Chambers, A. (1991). The Reading environment: How adults help children enjoy books. $\quad$ South Woodchester: Thimble Press.

Chambers, J. K. (1995). Sociolinguistic theory: Linguistic variation and its social significance. Cambridge: Blackwell.

Corbett, G. (1991). Gender. Cambridge: Cambridge University Press. 
Crawford, M. (1995). Talking difference: On gender and language. London: SAGE.

Eckert, P \& McConnell-Ginet, S. (1995). Constructing meaning, constructiong selves. In K. Hall \& M. Bucholtz (Eds.), Gender articulated: Language and the socially constructed self (pp. 470-507). New York: Routledge.

Fasold, R. (1984). The sociolinguistics of society. Oxford: Blackwell.

Goddard, A. \& Patterson, L. M. (2000). Language and gender. London: Routledge.

Hudson, R.A. (1980). Sociolinguistics. Cambridge: Cambridge University Press. Jahn, M. (2002). Narratology: A guide to the theory of narrative. In Poems, plays, and prose: A guide to the theory of literary genres (Pt. III). Retrieved April 10, 2003, from the World Wide Web: http://www.unikoeln.de/ ame02/pppn.htm

Labov, W. (1972). Sociolinguistic patterns. Philadelphia: University of Pennsylvania Press.

Labov,W. \& Fanshel, D.(1977). Therapeutic discourse: Psychotherapy as conversation. New York: Academic Press.

Livia, A. (2001). Pronoun envey: Literary uses of linguistic gender. Oxford: Oxford University Press.

McConnell-Ginet, S. (1988) "Language and gender", in F. Newmeyer (Ed.), Linguistics: The Cambridge survey. Vol. IV: The sociocultural context (pp. 75-99). Cambridge: Cambridge University Press.

McCormick, K.M. (1994). Gender and language. In R.E. Asher (Ed.), The encyclopedia of language and linguistics. (Vol.3, p.p. 1353-60). London: Elsevier Science. 
Poynton, C. (1989). Language and gender: Making the differernce. Oxford: Oxford University Press.

Romaine, S. (1994). "Sociolinguistics". In R.E. Asher (Ed.), The encyclopedia of language \& linguistics. (Vol. 7, p.p. 4005 -14). London: Elsevier.

Romaine, S. (2000). Language in society: An introduction to sociolinguistics. Oxford: Oxford University Press.

Spender, D. (1980). Man Made Language. London: Pandora.

Talbot, M. (1995). Fictions at work: Language and social practice in fiction. London: Longman.

Threadgold, T (2003). Cultural studies, critical theory and critical discourse analysis: Histories, remembering and futures. Linguistik online, 14, 2/03. Retrieved November 10, 2004 from the World Wide Web: http://www.linguistik-online.de/ 14_03/threadgold.html

Trudgill, P. (1972). Sex, covert prestige, and linguistic change in the urban British English of Norwich. Language in Society 1, 179-196.

Trudgill, P. (1984). Applied sociolinguistics. New York: Academic Press.

Wardhaugh, R. (1998). An introduction to sociolinguistics $\left(3^{\text {rd }}\right.$ ed.). Oxford: Blackwell.

Wodak, R. (1997). Introduction: Some important issues in the research of gender and discourse. In R. Wodak (Ed.), Gender and discourse (pp. 1-20). London: SAGE. 